Proc. of the XI Int. Conf. - Ion Implantation and other Applications of Ions and Electrons, Kazimierz Dolny 2016

\title{
Local Pseudoelastic Behaviour and Surface Characteristics of N Ion Implanted NiTi Shape Memory Alloy
}

\author{
N. Levintant-Zayonts ${ }^{a, *}$, L. KWiatKowski $^{b}$, Z. SwiateK ${ }^{c}$ And J. BrzOzOWska ${ }^{b}$ \\ ${ }^{a}$ Institute of Fundamental Technological Research, PAS, A. Pawinskiego 5B, 02-106 Warsaw, Poland \\ ${ }^{b}$ Institute of Precision Mechanics, Duchnicka 3, 01-796 Warsaw, Poland \\ ${ }^{c}$ Institute of Metallurgy and Materials Science, PAS, W.S. Reymonta 25, 30-059 Krakow, Poland \\ The main goal of the proposed paper is to present the results of the nitrogen ion implantation effects on \\ mechanical and corrosion properties of NiTi shape memory alloy. Local pseudoelasticity phenomena of NiTi \\ were determined using the ultra-low load applied system. The load-penetration depth curves show that lower \\ nitrogen fluence improves mechanical properties in the near surface layer but higher ion fluence leads to degradation \\ of pseudoelasticity properties. Corrosion resistance of $\mathrm{NiTi}$ in the Ringer solution was evaluated by means of \\ electrochemical methods. The results of potentiodynamic measurements in the anodic range for implanted NiTi \\ indicate a decrease of passive current density range in comparison with non-treated NiTi, without any signs related \\ to $\mathrm{Ni}$ release. The results of impedance measurements recorded at the corrosion potential show a capacitive \\ behaviour for all samples without clear predominance of one of them. It can be explained by the fact that this \\ result concerns the first stage of corrosion exposition. It is shown that nitrogen ion implantation leads to formation \\ of modified surface of improved physicochemical properties.
}

DOI: 10.12693/APhysPolA.132.210

PACS/topics: $62.20 . \mathrm{fg}, 81.40 . \mathrm{Jj}, 61.72 . \mathrm{U}-, 61.72 .-\mathrm{y}$

\section{Introduction}

NiTi alloy (Nitinol) is a well-known and wellestablished smart material which has been widely used in both non-medical [1] and medical applications [2] due to its extraordinary and unique properties such as shape memory effect (SME), pseudoelasticity (PE) and good biocompatibility. These properties are a result of reversible martensitic transformation in the shape memory materials $[3,4]$. A wide range of NiTi application leads to the increase of the role of their surface $[5,6]$. The issue of shape memory alloy (SMA) surface modification in the context of improving its characteristics on the one hand, and maintenance of their functional properties (SME and $\mathrm{PE}$ ) on the other hand, is a subject of research and development [7, 8]. Advanced micromechanical devices need the study of micro- and nanoscale functional-behaviour of SMAs. The method used to disclose small-scale mechanical properties of materials is the indentation test (in micro- and nanoscales). The indentation process creates high stress under the indenter and can induce a phase transformation in SMAs and initiate pseudoelasticity phenomena.

Due to the high content of $\mathrm{Ni}$ atoms (around 50\%), in the case of biomedical applications much attention has been paid to the surface modification of NiTi SMA to suppress the content of $\mathrm{Ni}$ in the superficial layer of the surface. In general, NiTi alloys are considered as the corrosion resistant material due to formation of titanium oxide layer but a risk of release of $\mathrm{Ni}$ ions creates a problem due to their toxicity [9]. The results of corrosion

*corresponding author; e-mail: neonila@ippt.gov.pl tests of NiTi alloys presented in majority of publications are based on analytical procedures or electrochemical methods. The latter are mainly recorded in the potentiodynamic mode $[10,11]$. From the course of polarization curves a susceptibility to pitting corrosion is usually assessed $[12,13]$. Some authors calculated corrosion currents from the extrapolation of the Tafel slopes [14, 15]. A growing number of papers published recently [16] describes an electrochemical impedance spectroscopy (EIS) as a tool for evaluation of surface properties, usually for short-time immersion, not exceeding $60 \mathrm{~min}$. The main information obtained from these results concerns characteristics of the oxide film consisting of a porous outer layer and an inner-barrier layer similarly to the bi-layered film structure found on Ti alloys. The values of resistivecapacitive parameters represent the protective properties of the film [16, 17]. Electrochemical measurements are performed in simulated body fluids (SBF), mainly socalled Hank solutions, Ringer solutions, artificial saliva, as well as $0.9 \% \mathrm{NaCl}$ and other similar media. The chemical content of these solutions slightly differs even within a solution type but the major corrosion agent which is chloride ion is common for all types of SBF.

In our previous work [18], it was demonstrated that $\mathrm{N}$ ion implantation suppressed $\mathrm{Ni}$ ions release and also caused change not only in a thin ion implanted layer, but also in the bulk material. However, the local pseudoelasticity phenomena and corrosion resistance are not well understood. Hence, in the present work, the effect of $\mathrm{N}$ implantation on the surface characteristics, indentation response (local pseudoelasticity phenomena) and corrosion behaviour of NiTi alloy has been investigated.

\section{Experimental details}

The material used in our experiment is a commercial $\mathrm{Ni}-50.7 \% \mathrm{Ti}$ alloy (Nitinol) in the sheet appearance 
(2.2 mm thick) produced by Memory Metalle $\mathrm{GmbH}$, Germany in the flat annealed form (in the austenitic (A) form). The sheet was cut into $5 \mathrm{~mm} \times 10 \mathrm{~mm}$ flat samples. Prior to ion implantation, the surface of samples was mechanically polished using a polish diamond compound $(9,3,1 \mu \mathrm{m})$ and finished with the $\mathrm{Al}_{2} \mathrm{O}_{3}$ suspension. Nitrogen ion implantation was performed using a typical semi-industrial implanter IMJON (Institute of Fundamental Technological Research, PAS, Warsaw) with the energy $50 \mathrm{keV}$, at two fluences: $D 1=10^{17} \mathrm{~cm}^{-2}$ and $D 2=14 \times 10^{18} \mathrm{~cm}^{-2}$. The evolution of the sample temperatures as a function of time during implantation was as follows: the temperature of the samples starts from room temperature, then monotonically increases and achieves values of $164^{\circ} \mathrm{C}$ and $189^{\circ} \mathrm{C}$ for doses D1 and D2, respectively, at the end of implantation process. As the phase transformation in NiTi can be also thermally induced, differential scanning calorimetry (DSC, Pyris-1) was used to specify the characteristic temperatures (phase transformation temperatures) As, Af, Ms, Mf. The definitions of these temperatures are as follows: As - start of austenitic phase formation in the heating process $\left(B 19^{\prime} \rightarrow B 2\right)$, Af - finish of austenitic phase formation in the heating process $\left(B 19^{\prime} \rightarrow B 2\right)$, Ms - start of martensitic phase formation in the cooling process $\left(B 2 \rightarrow B 19^{\prime}\right)$, Mf - finish of martensitic phase formation in the cooling process $\left(B 2 \rightarrow B 19^{\prime}\right)$.

The effect of ion implantation on mechanical properties (local superelasticity phenomena) was determined using a commercially available ultra-low load indentation system, the Nano Indenter (CSM Instruments SA, Switzerland). In the majority of nano- and micro-indentation tests reported in the literature [19] sharp indenters (Vickers, Berkovich) are applied and the Young modulus and hardness are specified using the Oliver-Pharr method. However, this method was originally derived for elasticplastic materials and in the case of shape memory alloys its results should be interpreted very carefully as these materials exhibit completely different stress-strain behaviour from that of the elastic-plastic materials. In the presented indentation test diamond spherical tips of different radii $(200,20$, and $2 \mu \mathrm{m})$ were applied. When the radius of spherical tip decreases, the stress state is more localized. In the case of the smallest tip $(R=2 \mu \mathrm{m})$ the stress concentration is practically confined to thin layer [20]. The concentration is strictly controlled by the penetration depth. However, this kind of tips does not induce exhaustive stress concentrations the so-called sharp indenters (Vickers, Berkovich) that due to sharp edges cause large strains, even for small penetration depths at the beginning of indentation test. When SMA in the austenitic state is indented with a sharp indenter, a local plastic deformation takes place practically at the start of indentation test and closed hysteresis loops resulting from the phase transformation cannot been observed. For this reason, the spherical indenter was used in our studies. The micro- and nanoindentation tests were applied to observe a local phase transformation and superelasti- city phenomena in different scales i.e. when the deformations are induced mainly in the thin implanted layer, in the layer and substrate and mainly in the substrate. The variation of load-penetration depth curves was analyzed. The following indentation tests were performed:

1) Microindentation test with the spherical indenter of $R=200 \mu \mathrm{m}$, for the loads $4 \mathrm{~N}$.

2) A more shallow near-surface zone was investigated using the spherical indenter of the smaller radius, $R=$ $20 \mu \mathrm{m}$, for the loads $250 \mathrm{mN}$.

3) Nanoindentation test with the spherical indenter of the radius $R=2 \mu \mathrm{m}$ for the loads $0.5 \mathrm{mN}$ and $1 \mathrm{mN}$.

All indentation experiments were performed at room temperature. The holding time for indentation measurements accounted for two seconds.

Electrochemical measurements are performed in the Ringer solution of the composition: $\mathrm{NaCl} 8.6 \mathrm{~g} / \mathrm{l}, \mathrm{KCl}$ $0.3 \mathrm{~g} / \mathrm{l}, \mathrm{CaCl}_{2} 0.243 \mathrm{~g} / \mathrm{l}$. The $\mathrm{pH}$ of the solution is equal to 5.7. The three-electrode electrochemical cell composed of the working electrode i.e. the test sample of the area $0.38 \mathrm{~cm}^{2}$ exposed to the solution, the saturated calomel electrode (SCE) as the reference electrode and the platinum mesh as the auxiliary electrode was used. Impedance measurements and data analysis were made using SolartronTransfer Function Analyser / Electrochemical Interface 1260/1287 with the software Corrware, Corrview, Zplot, ZView. The impedance measurements were performed in the frequency range $10^{5}-10^{-2} \mathrm{~Hz}$ under the amplitude of the sinusoidal signal $10 \mathrm{mV}$ and DC maintained at the value of the stationary potential attained after $1 \mathrm{~h}$ of immersion in the Ringer solution.

Wide angle X-ray scattering (WAXS) measurements were performed using the Bruker D8 Discover (Germany) diffractometer operating at the voltage $40 \mathrm{kV}$ and the current $40 \mathrm{~mA}$. $\mathrm{Cu} K_{\alpha}$ radiation was used $(\lambda=1.5406 \AA)$. Measurements were performed in the reflection mode, using the Bragg-Brentano geometry, with focusing optics composed of the Goebel mirror with the deflection $0.677^{\circ}$ and $0.3 \mathrm{~mm}$ circular slit and $0.3 \mathrm{~mm}$ collimator. The highly sensitive Lynx Eye 1-D silicon strip detector was used in the continuous scan mode. The scans were performed in the grazing incidence mode at the constant angle of incident beam, $\omega$, in the range $0-10^{\circ}$ with the $0.25^{\circ}$ increment. Measurements were done in the diffraction angle range, $2 \theta, 30-65^{\circ}$ at the sampling rate $0.5 \mathrm{~s}$ per point. Prior to the grazing incidence measurements, precise position of the sample was determined from the measurements at a low angle of incident beam $\left(\omega=1^{\circ}\right)$ while varying position of the sample in the direction normal to the sample surface, axis. The sample position was determined as "characterized by the maximum intensity from the 110 austenite diffraction peak".

\section{Results and discussion}

It is known that NiTi of SMAs exhibit three different phases: $B 2$ austenite (A), monoclinic $B 19^{\prime}$ martensite (M) and trigonal $R$-phase (R) [3]. Under the solutiontreated conditions, near-equiatomic NiTi alloys, typically 
containing $49-51$ at. $\% \mathrm{Ni}$, exhibit a single-stage transformation between the $B 2$ austenite and the $B 19^{\prime}$ martensite. Under certain conditions (thermal cycling, cold working, partial annealing and ageing), the R-phase can appear between austenite and martensite. Among these three phases, several transformation sequences are possible, with various combinations of: $\mathrm{A}-\mathrm{R}, \mathrm{A}-\mathrm{M}$, and $\mathrm{R}-\mathrm{M}$ transformations $[3,4]$. Phase transformation from auste-

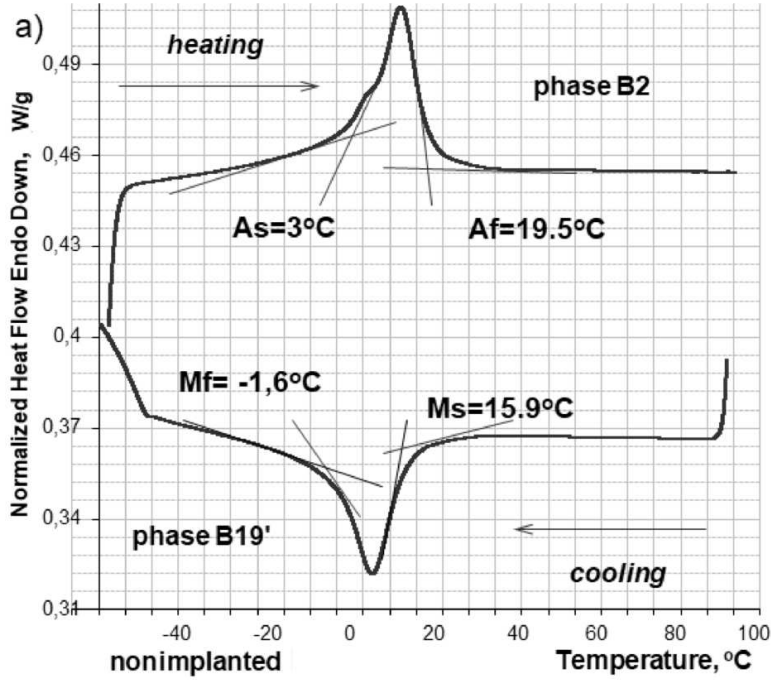

nite (high temperature phase-stable under low stress, in a cubic form with $B 2$ symmetry) to martensite (phasestable under adequate higher stress conditions, monoclinic form with $B 19^{\prime}$ symmetry) can be induced in SMAs above the Af temperature by loading material to exceed the critical value of transformation stress. The reverse phase transformation from martensite to austenite is observed when material is unloaded.

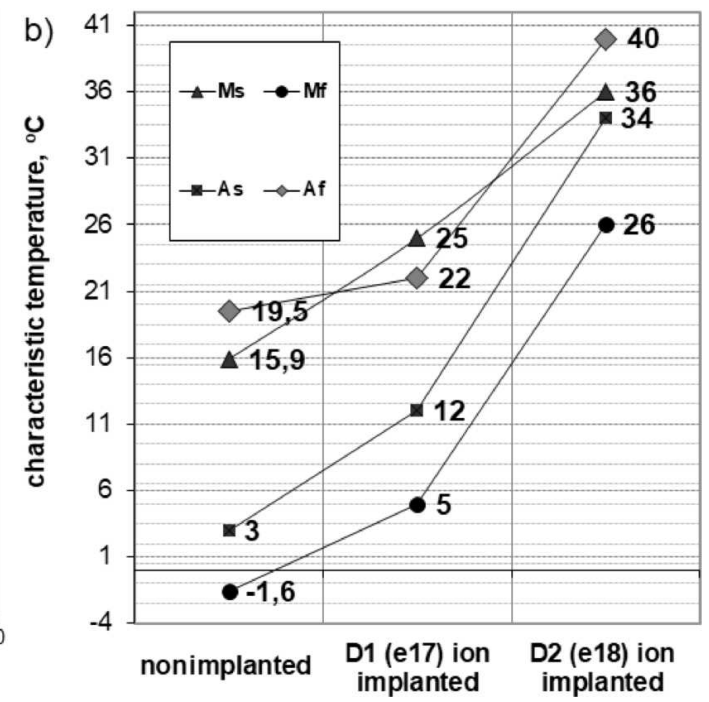

Fig. 1. Characteristic temperatures obtained by the DSC test for the non-implanted NiTi (a) and nitrogen ion implanted $\left(D 1=10^{17} \mathrm{~cm}^{-2}\right.$ and $\left.D 2=10^{18} \mathrm{~cm}^{-2}\right) \mathrm{NiTi}(\mathrm{b})$.

The determined transformation temperatures of nonimplanted NiTi: $M s=15.9^{\circ} \mathrm{C}, M f=-1.6^{\circ} \mathrm{C}, A s=$ $3{ }^{\circ} \mathrm{C}, 4 A f=19.5^{\circ} \mathrm{C}$ are shown in Fig. 1a. At room temperature this material is in the austenitic state and exhibits pseudoelastic properties. For the sample implanted with the fluence $D 1$, the calorimetric analysis (Fig. 1b) showed that during cooling from the high temperature phase, the forward transformation starts at $M s=25^{\circ} \mathrm{C}$, and ends at $5^{\circ} \mathrm{C}(M f$ - at which formation of martensite is completed). The reverse transformation starts at $A s=12{ }^{\circ} \mathrm{C}$ and ends at $A f=22{ }^{\circ} \mathrm{C}$. A similar trend is observed for the implanted fluence $D 2$, and the characteristic transformation temperatures are the following: $M s=36^{\circ} \mathrm{C}, M f=26^{\circ} \mathrm{C}, A s=34^{\circ} \mathrm{C}$ and $A f=40^{\circ} \mathrm{C}$. After the irradiation process all temperatures of martensite transformation (start/finish) are shifted to higher values. The change of transformation temperatures can be attributed to the formation of a complex structure in the near-surface region after the ion implantation, additionally - to the influence of increase in the temperature due to beam irradiation. The temperature of the samples starts from room temperature, then monotonically increases and achieves the values of $170^{\circ} \mathrm{C}$ and $240^{\circ} \mathrm{C}$ for the doses $D 1$ and $D 2$ fluences, respectively at the end of implantation process.

Figure 2 presents the indentation curves in different scales for non-implanted and ion implanted $(D 1=$ $10^{17} \mathrm{~cm}^{-2}, D 2=10^{18} \mathrm{~cm}^{-2}$ ) NiTi. Figure 2a shows the different response in the indentation test $(R=200 \mu \mathrm{m})$ of non-implanted NiTi and the samples implanted with nitrogen $D 1$ and $D 2$ fluences. Slight stiffening for $D 1$ ion implanted NiTi is noted. It can be observed that the latter exhibits a greater compliance. In addition, the area between the loading and unloading curve (hysteresis loop) is much wider in the case of $D 2$ dose implanted sample. The occurrence of residual penetration depth on the D2 ion implanted samples indicates that the tested material does not exhibit pseudoelastic properties. For the dose $D 1$ implanted sample the shape of load-penetration curves is closer to that observed for the virgin sample in the austenitic state. This can be a result of the austenitic phase content, that is greater in the $D 1$ sample than in the $D 2$ one, as for the $D 1$ sample Af is closer to room temperature. The shape of unloading curves and the residual penetration depth observed in Fig. 2a indicate that a phase transformation process occurs in the indentation test but it is not completed.

The difference between the indentation curves corresponding to the low and high fluence implanted samples is greater for indentation performed with a tip of smaller radius, where the penetration depth is only twice larger than the thickness of modified layer [18, 21] (Fig. 2b). For $250 \mathrm{mN}$ loads there are observed the residual penetration depths that are greater for higher implantation D2 fluence. Thus the material implanted with smaller $D 1$ fluence is much stiffer than that implanted with $D 2$ fluence. Nevertheless the shape of load-penetration curves is similar to closed loops, and in the case of fluence 

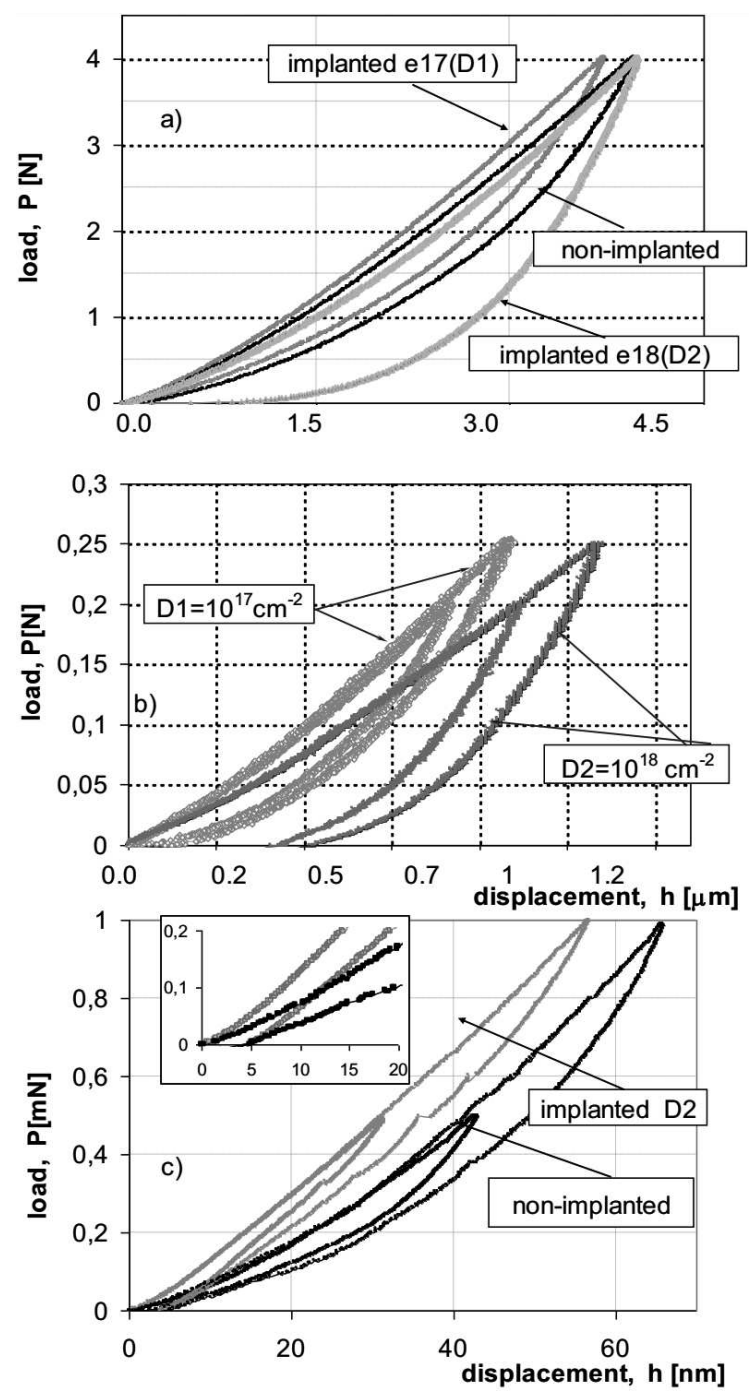

Fig. 2. Indentation curves in different scales: (a) a spherical tipped indenter $R=200 \mu \mathrm{m}$, (b) a spherical tipped indenter $R=20 \mu \mathrm{m}$, (c) a spherical tipped indenter $R=2 \mu \mathrm{m}$ - for the non-implanted and ion implanted $\left(D 1=10^{17} \mathrm{~cm}^{-2}, D 2=10^{18} \mathrm{~cm}^{-2}\right)$ NiTi alloy.

D2 implanted samples a larger area is enclosed between loading and unloading curves. The results of microindentation tests discussed above should take into consideration the indented material as a kind of composite surface layer-bulk material where both components influence the shape of load-penetration curve. The ratio of surface layer volume and substrate volume engaged in each test depends on the tip radius and penetration depth. The results of microindentation test indicate that the stiffness of the indented material decreases if one of the implanted ions fluences increases. This effect should be attributed to the change of bulk material properties rather than the modification of thin surface layer, as the penetration depth is generally much greater than the modified layer thickness. However, one can notice some effects of the layer modification that are consistent with the observation presented in other works [22, 23].
The most distinct difference between the loadpenetration curves for implanted with $D 1$ fluence and non-implanted NiTi can be observed in Fig. 2c. The implanted surface exhibits much higher stiffness and amnesia of superelasticity phenomena. There is no closed hysteresis loop. On the non-implanted sample the shape of the hysteresis loop is similar to the case of the microindentation test.

The results of the micro- and nanoindentation tests revealed the occurrence of larger residual depths for the implanted samples than for the non-implanted one. This residual depth shows clearly that at room temperature the PE disappears after the high fluence $(D 2)$ ion implantation. It is assumed that high fluence of ion implantation treatment can generate modified surface layers with a gradient of defects $[18,22]$, change of microstructure and also compressive residual stress. The results of micro- and nanoindentation tests are correlated with the results of DCS test where we can observe the increase of all transformation temperatures, which is an attribute of complex structure formation in the near-surface region after the ion implantation.

Further studies are needed to investigate the relationship between the structure of the ion implanted layers, its mechanical and corrosion properties as well as conditions of the implantation process because for these SMAs the change of temperature during the ion implantation treatment is very most important.

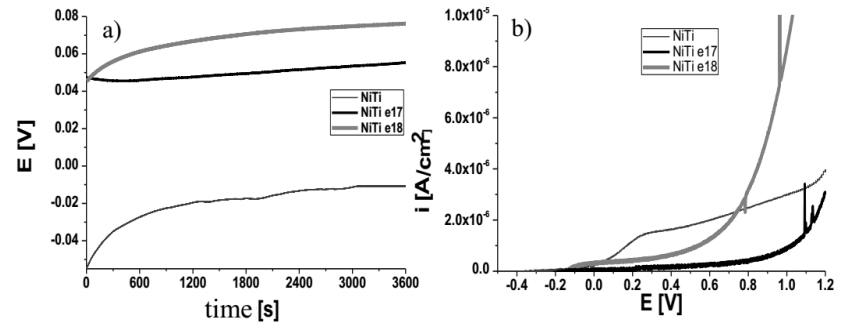

Fig. 3. Course of the open circuit potential (a) and anodic polarization curves (b) for nonimplanted and $\mathrm{N}$ ion implanted NiTi alloy. $\left(D 1=10^{17} \mathrm{~cm}^{-2}\right.$ and $D 2=$ $10^{18} \mathrm{~cm}^{-2}$.

Prior to each electrochemical measurement an open circuit potential was measured in order to satisfy the stationary conditions of the experiment. The values of start and final electrode potentials after $1 \mathrm{~h}$ of immersion are listed in Fig. 3. It can be concluded that the changes of $E$ with time are minor for both implanted samples while for the bare NiTi alloy a slight trend towards positive values is recorded. More noble potential values for the implanted samples indicate their lower corrosion likelihood in comparison to bare NiTi. It is especially important in terms of implants where $\mathrm{Ni}$ release to the body physiological fluids has to be avoided. The results of anodic polarization of the tested samples while immersed in the Ringer solution are shown in Fig. 3b. A wide plateau of current density within the potential 


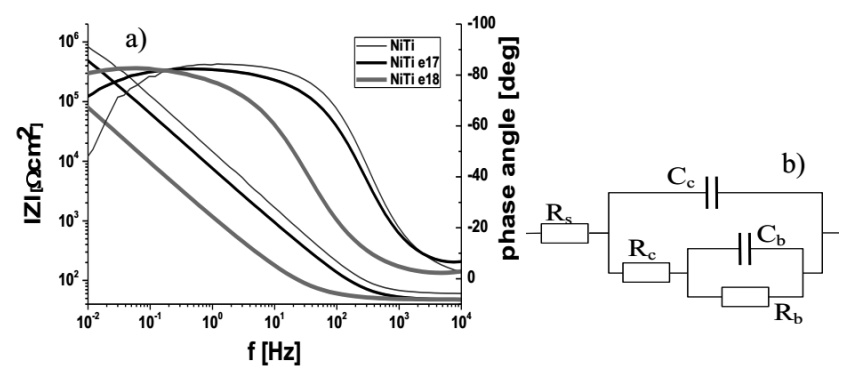

Fig. 4. Bode plots for NiTi before and after ion implantation. The results of measurements in the Ringer solution after $1 \mathrm{~h}$ (a) and equivalent circuit used for results interpretation (b). $R_{s}$ - solution resistance, $R_{c}$ - resistance of the porous layer, $C_{c}$ - capacitance of the porous layer, $R_{b}$ - resistance of the barrier layer, $C_{b}$ - capacitance of the barrier layer.

range $-0.2 \mathrm{~V}$ to $0.9 \mathrm{~V}$ for the sample treated in the process of ion implantation by nitrogen with the fluence of $D 1=10^{17} \mathrm{~cm}^{-2}$ is obtained. Passive current density attains approximately $10^{-8} \mathrm{~A} / \mathrm{cm}^{-2}$. A change of the fluence to $D 2=10^{18} \mathrm{~cm}^{-2}$ leads to a less stable passive state and higher current densities $\left(\approx 10^{-7} \mathrm{~A} / \mathrm{cm}^{-2}\right)$. On the contrary, the bare NiTi alloy exhibits the low passive current density $\left(\approx 10^{-8} \mathrm{~A} / \mathrm{cm}^{-2}\right)$ at the beginning of polarization from - to $-0.050 \mathrm{~V}$ and at $0 \mathrm{~V}$ a moderate rise of current density is recorded with its inhibition beyond $0.2 \mathrm{~V}-0.3 \mathrm{~V}$. This potential range corresponds to the occurrence of the redox reaction $\mathrm{Ni}^{0}-2 \mathrm{e} \rightarrow \mathrm{Ni}^{2+}[24]$. Although current densities for the NiTi alloy in this potential range are several times higher than the corresponding values for the implanted samples, the order of $10^{-6} \mathrm{~A} / \mathrm{cm}^{-2}$ for NiTi indicates that the surface is still in the passive state and expected $\mathrm{Ni}^{2+}$ release takes place locally in the pores of the passive film and is limited by its quality. For larger anodic potentials a steep increase of currents density is observed, particularly for the implanted samples. This is a result of oxygen evolution as the main reaction but other side reactions cannot be excluded. The surface modified under the D2 fluence facilitates an oxygen evolution and this process starts already at $0.7 \mathrm{~V}$ while for the sample implanted with the $D 1$ fluence it starts around $1.1 \mathrm{~V}$. Oxygen evolution on the surface of the bare NiTi alloy proceeds hardly due to a poor conductivity of titanium oxides grown on this surface during the anodic polarization. In the all performed experiments no pitting corrosion is observed.

In order to assess corrosion resistance including protective properties of surface layers similar comparative measurements are performed by means of electrochemical impedance spectroscopy. The results in the form of the Bode plots i.e. frequency dependence of impedance modulus $|Z|$ and phase angle $\Theta$ are shown in Fig. 4a and the equivalent circuit used for the interpretation of EIS results in Fig. 4b. The impedance spectra show a capacitive behaviour for all samples in a wide range of frequencies starting with $f=10^{2} \mathrm{~Hz}$ with a slope of
$|Z|_{f \rightarrow 0}$ close to -1 which is related to high protectiveness of the material or surface film. A slightly different course of the plot for the sample implanted under the fluence of $D 2=10^{18} \mathrm{~cm}^{-2}$ is observed. The impedance spectrum is shifted towards lower frequencies which could be linked to the effect of lower thickness of the passive film since $C=\varepsilon \varepsilon_{0} A / d(\varepsilon-$ dielectric constant of the oxide film, $\varepsilon_{0}$ - vacuum permittivity, $A$ - surface area, $d$ - thickness of the oxide film). The impedance data are fitted to the electrical equivalent circuit presented in Fig. 3b which is widely accepted for interpretation of the EIS results of NiTi alloys [25]. This assumes a bilayer structure of the surface film as indicated in Fig. 3b [21]. Due to the slight deviation from the pure capacitances a constant phase element (CPE) is used instead of $\mathrm{C}$.

The impedance associated with $\mathrm{CPE}$ is given [26]: $Z=1 / Q(\mathrm{j} \omega)^{n}$, where the constant phase element parameter $Q=C$ when $n=1, \mathrm{j}^{2}=-1$. The values of electrochemical parameters drawn from the fitting procedure using the ZView software are presented in Table I.

TABLE I

Equivalent circuit parameters obtained from the EIS data measured in the Ringer solution.

\begin{tabular}{c|c|c|c|c|c|c|c}
\hline \hline Sample & $\begin{array}{c}R_{s} \\
{\left[\Omega \mathrm{cm}^{2}\right]}\end{array}$ & $\begin{array}{c}Q_{c} \\
{\left[\frac{\mu \mathrm{Fs}^{n-1}}{\left.\mathrm{~cm}^{2}\right]}\right]}\end{array}$ & $n_{c}$ & $\begin{array}{c}R_{c} \\
{\left[\Omega \mathrm{cm}^{2}\right]}\end{array}$ & $\begin{array}{c}Q_{b} \\
{\left[\frac{\mu \mathrm{Fs}^{n-1}}{\left.\mathrm{~cm}^{2}\right]}\right]}\end{array}$ & $n_{b}$ & $\begin{array}{c}R_{b} \\
{\left[M \Omega \mathrm{cm}^{2}\right]}\end{array}$ \\
\hline NiTi & 60.0 & 12 & 0.92 & 274 & .64 & 1.0 & 1.6 \\
\hline NiTi 18 & 48.7 & 110 & 0.91 & 232 & 51 & 0.9 & 2.6 \\
\hline NiTi 17 & 48.1 & 21 & 0.92 & 2200 & 3.1 & 0.9 & 3.0
\end{tabular}

In general, the best protectiveness is obtained for the $\mathrm{N}$ implanted sample under the fluence of $D 1=10^{17} \mathrm{~cm}^{-2}$. This is proved by the highest resistance of both layers. However, the lowest capacitive parameters for bare NiTi indicate development of the thickest oxide film. Chemical diversity of the surface after implantation at $D 2=10^{18} \mathrm{~cm}^{-2}$ identified in the previous chapter leads to the decrease of protective properties of the surface which is reflected by the lower resistive and higher capacitive parameters. In general, one can conclude that differences between the electrochemical parameters for the investigated samples are not large, and longer immersion times and/or other corrosion loads are needed for their degradation.

The X-ray diffraction data were analyzed using the crystallographic database PDF4 [Joint Committee on Powder Diffraction Standards, JCPDS in: International Centre for Diffraction Data. Powder Diffraction File-PDF4, ICDD, (CDROM), Pennsylvania (2009)]. Figure 5a presents the X-ray diffraction patterns of non-implanted NiTi sample recorded at different incident angles $\omega$ in the range of $0-10^{\circ}$ with the increment of $0.25^{\circ}$. The penetration depth of X-ray $\mathrm{Cu} K_{\alpha}$ radiation in the $\mathrm{NiTi}$ sample (the material density $6.5 \mathrm{~g} / \mathrm{cm}^{3}$ ) under the experimental conditions varies from 0 to about $5.6 \mu \mathrm{m}$. From the obtained results, it can be seen that the alloy is composed of one phase - austenite A crystallizing in the 


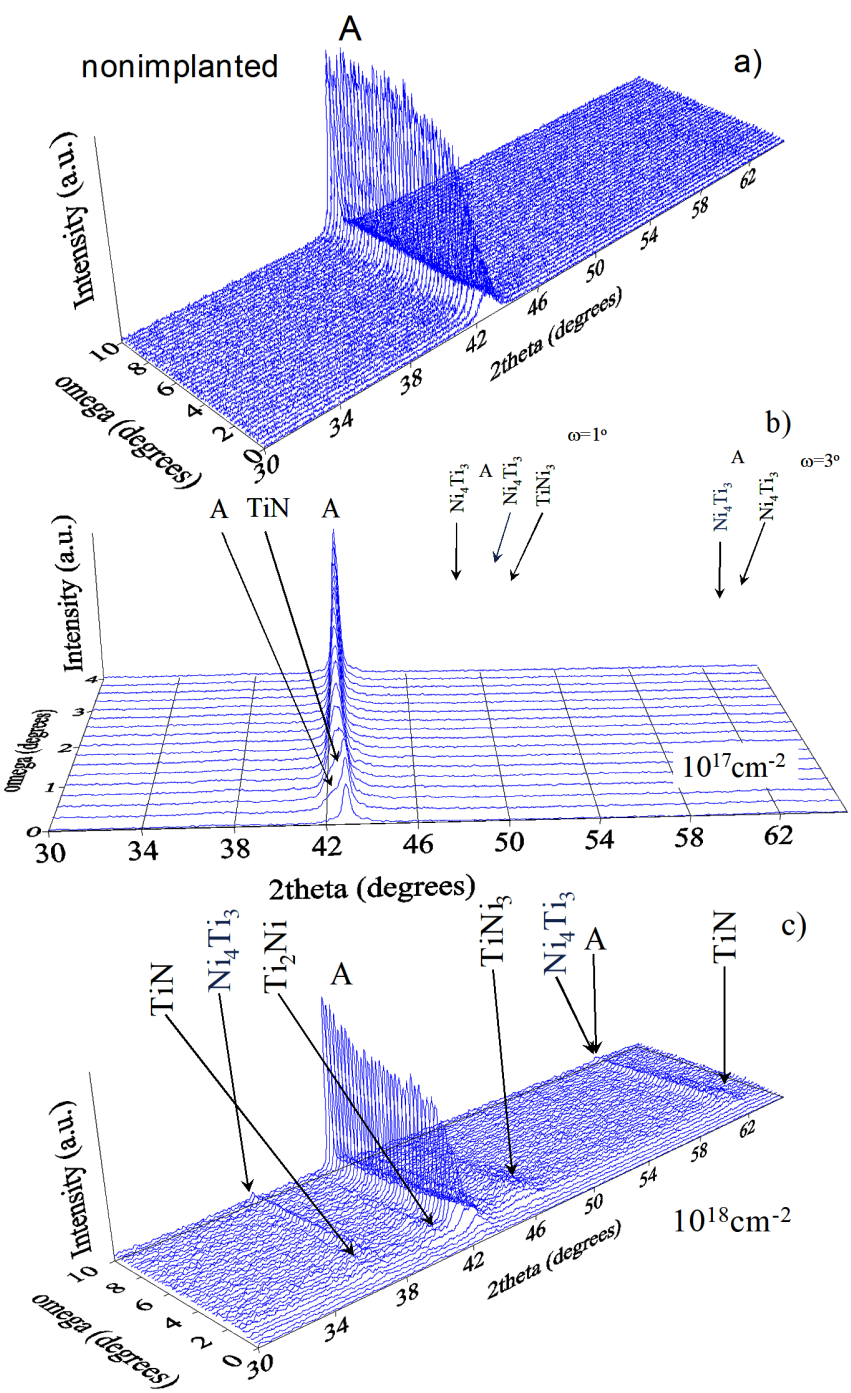

Fig. 5. XRD pattern of NiTi alloy before and after N ion implantation.

cubic system with the space group $\operatorname{Pr} \overline{3} m$. As can be seen from the diffraction patterns of the non-implanted NiTi sample in Fig. 5a, together with the decreased value of the incident angle (the decreased X-ray penetration depth in material), increased full width at half maximum (FWHM) of the peak A is observed. Such a change in the form of the diffraction line profile is associated with reduction in crystallite size and increase in deformation of its crystal lattice caused by structural defects. The observed microstructural changes reach a depth of about $1 \mu \mathrm{m}$ and were caused by the applied surface treatment.

The X-ray diffraction patterns of the ion implanted NiTi alloy with the fluence of $10^{17} \mathrm{~cm}^{-2}$ recorded at different incident angles $\omega$ in the range of $0-4^{\circ}$ with the increment of $0.25^{\circ}$ are shown in Fig. 5b. It can be stated that the near-surface layer of this sample consists of four phases. The diffraction lines derived from A, TiN, $\mathrm{TiNi}_{3}$ and $\mathrm{Ni}_{4} \mathrm{Ti}_{3}$ were registered (see the inset in Fig. 5b). The dominant phase is austenite, crystallizing in the cubic system with the space group $P m \overline{3} m$. TiN phase (dominant phase to the depth of about $300 \mathrm{~nm}$ ) crystallizes in the cubic system (space group $F m \overline{3} m$, PDF Card Number: 04008-4976) whereas $\mathrm{TiNi}_{3}$ that occurs up to the depth of $660 \mathrm{~nm}$ crystallizes in the hexagonal system (space group $P 6_{3} / m m c$, PDF card number: 04-007-8520). The fourth phase is $\mathrm{Ni}_{4} \mathrm{Ti}_{3}$ crystallizing in the rhombohedral system (space group $R \overline{3}$, PDF card number: 04-001-1903) and occurs up to the depth of $1.9 \mu \mathrm{m}$. It should be noted that each phase is fine-grained, as evidenced by the observed broadening of the diffraction line.

From the analysis of the X-ray diffraction patterns, it is evident that the ion implanted NiTi alloy with a fluence of $10^{18} \mathrm{~cm}^{-2}$ exhibits five phases: austenite (A), TiN, $\mathrm{TiNi}_{3}, \mathrm{Ni}_{4} \mathrm{Ti}_{3}$ and $\mathrm{Ti}_{2} \mathrm{Ni}$. This additional fifth phase crystallizes in the cubic system (space group $F d \overline{3} m, \mathrm{PDF}$ card number: 04-007-5177) (Fig. 5c). As follows from the obtained results for the ion-implanted NiTi alloy with higher ion fluence both the contribution of the individual phases and the depth of their occurrence are increased. The $\mathrm{Ni}_{4} \mathrm{Ti}_{3}$ phase exists up to the depth of $5.6 \mu \mathrm{m}$, TiN - up to about $1.3 \mu \mathrm{m}$ and the $\mathrm{Ti}_{2} \mathrm{Ni}$ and $\mathrm{TiNi}_{3}$ phases - up to about $3.6 \mu \mathrm{m}$.

It should be noted that the X-ray diffraction pattern at the incident angle equal to $0.25^{\circ}$ has the characteristic nanocrystalline and amorphous-like shape of the intensity distribution. This may confirm the fact that heavily damaged (amorphized) and nanocrystalline materials are formed during an ion implantation. As the obtained results indicate, to the depth of about $170 \mathrm{~nm}$ the material contains a near-surface amorphous-like layer and a number of nanocrystalline inclusions of identified phases within its bulk.

\section{Conclusions}

In this study the NiTi shape memory alloy was modified by the $\mathrm{N}$ ion implantation. The surface characteristics including corrosion resistance, microstructure and phase changes as well as local pseudoelasticity behaviour were investigated. The main conclusions are summarized as follows:

- Nitrogen ion implantation of NiTi SMA alloys leads to extreme changes of mechanical properties. The surface obtained with the fluence $D 1$ exhibits increased stiffness while preserving of pseudoelasticity and the application of a larger fluence i.e. D2 leads to a destruction of pseudoelasicity regardless of the testing volume of the material.

- Nitrogen ion implantation decreases the risk of $\mathrm{Ni}^{2+}$ release to the surrounding environment due to formation of stable TiN film increasing a distance of $\mathrm{Ni}$ in the bulk alloy to the superficial layer. Neither bare NiTi nor implanted samples were susceptible to the pitting corrosion. The process intensity in terms of ion fluence affects physicochemical properties of the surface layer. With the fluence $D 1$ the surface is more uniform providing better 
protectiveness against corrosion in comparison with the fluence D2. The differences in corrosion resistance between the investigated samples are not large and longer immersion times and/or other, more aggressive corrosion loads are needed for their accelerated degradation.

- All temperatures (start/finish) of martensite transformation are shifted to higher values.

\section{Acknowledgments}

The present research was supported by the National Science Centre (NCN) in Poland under grant no. 2013/09/D/ST8/04011.

The authors wish to extend thanks to Dr. A. Gradys (the Institute of Fundamental Technological Research, PAS) for the performance of XRD and DSC measurements.

\section{References}

[1] M.R. Gorji, S. Sanjabi, Mater. Lett. 73, 179 (2012).

[2] G. Laplanche, J. Pfetzing-Micklich, G. Eggler, Acta Mater. 78, 144 (2014).

[3] A. Ziolkowski, B. Raniecki, S. Miyazaki, Mater. Sci. Eng. A 378, 86 (2004).

[4] Naval Research Laboratory; General Nitinol Effects Memry Corporation.

[5] S. Shabalovskaya, J. Anderegg, J. Van Humbeeck, Acta Biomater. 4, 447 (2008).

[6] L. Tan, W.C. Crone, Acta Mater. 50, 4449 (2002).

[7] N. Levintant, Vacuum 81, 1283 (2007).

[8] K. Takeda, R. Mitsui, H. Tobushi, S. Homma, N. Levintant-Zayonts, S. Kucharski, Arch. Mech.67, $293(2015)$.

[9] M. Es-Souni, Bioanal. Chem. 381, 557 (2005).

[10] Y.L. Chan, S.L. Wu, X.M. Liu, P.K. Chu, K.W.K. Yeung, W.W. Lu, A.H.W. Ngan, K.D.K. Luk, D. Chan, K.M.C. Cheung, Surf. Coat. Technol. 202, 1308 (2007).
[11] R.W.Y. Poon, J.P.Y. Ho, Xuanyong Liu, C.Y. Chung, P.K. Chu, K.W.K. Yeung, W.W. Lu, K. Cheung, Thin Solid Films 488, 20 (2005)).

[12] X.M. Liu, S.L. Wu, P.K. Chu, C.Y. Chung, C.L. Chu, Y.L. Chan, K.W.K. Yeung, W.W. Lu, K.M.C. Cheung, K.D.K. Luk, Surf. Coat. Technol. 202, 2436 (2008).

[13] R.E. McMahon, J. Ma, S.V. Verkhoturov, D. MunozPinto, I. Karaman, F. Rubitschek, H.J. Maier, M.S. Hahn, Acta Biomater. 8, 2863 (2012).

[14] Y. Cheng, C. Wei, K.Y. Gan, L.C. Zhao, Surf. Coat. Technol. 176, 261 (2004).

[15] N. Schevchenko, M.-T. Pham, M.F. Maitz, Appl. Surf. Sci. 235, 126 (2004)).

[16] M.R. Souto, M.M. Laz, R.L. Reis, Biomaterials 24 4213 (2003))

[17] S.L. de Assis, S. Wolynec, I. Costa, Electrochim. Acta 51, 1815 (2006).

[18] S. Kucharski, N. Levintant-Zayonts, J. Luckner, Mater. Des. 56, 671 (2014).

[19] D. Jarząbek, A. Kaufmann, H. Schift, Z. Rymuza, T. Jung, Nanotechnology 25, 215701 (2014).

[20] S. Kucharski, Z. Mróz, Int. J. Mech. Sci. 49, 1238 (2007)).

[21] T. Czeppe, N. Levintant-Zayonts, Z. Swiatek, M. Michalec, O. Bonchyk, G. Savitskij, Vacuum 83, S214 (2009).

[22] H. Pelletier, D. Muller, P. Mille, J.J. Grob, Surf. Coat. Technol. 158-159, 309 (2002).

[23] Z. Tingting, L. Yan, L. Yong, Z. Xinqing, J. Mech. Behav. Biomed. Mater. 13, 174 (2012).

[24] W.M. Latimer, The Oxidation States of Elements and Their Potentials in Aqueous Solutions, 2nd ed. Prentice-Hall, New York 1952, p. 206.

[25] N. Figueira, T.M. Silva, M.J. Carmezim, J.C.S. Fernandes, Electrochim. Acta 54, 921 (2009).

[26] J.R. Scully, R.G. Kelly, in: ASM Handbook Corrosion, Vol. 13, ASM International, 2003, p. 73. 